\title{
VEGF Is Involved in the Increase of Dermal Microvascular Permeability Induced by Tryptase
}

\author{
Qianming Bai, ${ }^{1}$ Xiaobo Li, ${ }^{1}$ Xinhong Wang, ${ }^{1}$ Yali Xu, ${ }^{1}$ Li Wang, ${ }^{1}$ \\ Qingyong Zhang, ${ }^{2}$ and Lianhua Yin ${ }^{1}$ \\ ${ }^{1}$ Department of Physiology and Pathophysiology, Fudan University Shanghai Medical College, Shanghai 200032, China
${ }^{2}$ Department of Cardiology, Shanghai Jiaotong University Affiliated Sixth People's Hospital, Shanghai 200032, China
}

Correspondence should be addressed to Xiaobo Li, xbli@fudan.edu.cn

Received 5 February 2012; Accepted 13 March 2012

Academic Editors: E. Pasmatzi and A. Zalewska

Copyright ( 2012 Qianming Bai et al. This is an open access article distributed under the Creative Commons Attribution License, which permits unrestricted use, distribution, and reproduction in any medium, provided the original work is properly cited.

Tryptases are predominantly mast cell-specific serine proteases with pleiotropic biological activities and play a critical role in skin allergic reactions, which are manifested with rapid edema and increases of vascular permeability. The exact mechanisms of mast cell tryptase promoting vascular permeability, however, are unclear and, therefore, we investigated the effect and mechanism of tryptase or human mast cells (HMC-1) supernatant on the permeability of human dermal microvascular endothelial cells (HDMECs). Both tryptase and HMC-1 supernatant increased permeability of HDMECs significantly, which was resisted by tryptase inhibitor APC366 and partially reversed by anti-VEGF antibody and SU5614 (catalytic inhibitor of VEGFR). Furthermore, addition of tryptase to HDMECs caused a significant increase of mRNA and protein levels of VEGF and its receptors (Flt-1 and Flk-1) by Real-time RT-PCR and Western blot, respectively. These results strongly suggest an important role of VEGF on the permeability enhancement induced by tryptase, which may lead to novel means of controlling allergic reaction in skin.

\section{Introduction}

Mast cells are critical for allergic inflammatory responses and cutaneous hypersensitivity reactions, such as atopic dermatitis, contact dermatitis, eczema and nettle rash [14]. Mast cells can be activated to release a diverse array of potent biologically active products and cytokines [5-7]. The major secretory product of human mast cells is the serine proteinase tryptase (tetrameric trypsin-like substrate specificities), which is emerging as a major mediator of allergic disease and as a promising target for therapeutic intervention [8]. Human mast cells contain at least two tryptases, $\alpha$-tryptase and $\beta$-tryptase. Human mature $\beta$ tryptase is stored in the mast cells granules and released upon activation while $\alpha$-tryptase is apparently processed only to the proenzyme stage and is constitutively secreted along with $\beta$ protryptase $[8,9]$. In healthy individuals, only $\alpha$-tryptase can be detected whereas $\beta$-tryptase is undetectable. However, significant elevations of circulating $\beta$-tryptase levels were observed in patients with allergic diseases $[10,11]$.
The common clinical sign of allergic hypersensitivity reactions in skin is edema, which caused by increases in vascular permeability $[12,13]$. It is reported that tryptase may contribute to vascular permeability by the direct or indirect generation of bradykinin from kininogens [14]. Mast cell tryptase increases intracellular $\mathrm{Ca}^{2+}$, leading to elevation of paracellular permeability of colonocytes [15]. Intradermal injection of tryptase or mast cell secretagogue compound $48 / 80$ in rats can induce the immediate cutaneous reaction and increase dermal microvascular permeability, which can be inhibited by potent and specific tryptase inhibitor nafamostat or synthetic tryptase inhibitor APC366 $[16,17]$. However, the mechanism of enhancement of vascular permeability induced by tryptase is still not clear and need further study.

Vascular endothelial growth factor (VEGF), an endothelial cell mitogen that promotes angiogenesis, was initially identified as a vascular permeability factor (VPF) [18, 19]. VEGF interacts with two high-affinity tyrosine kinase receptors, VEGFR-1 (Flt-1) and VEGFR-2 (KDR/Flk-1), 
to increase microvascular permeability and induce angiogenesis [20]. In patients with delayed hypersensitivity, the amount of VEGF produced in lesional scales was approximately 25 times higher than that in normal stratum corneum [21]. In patients with allergic contact dermatitis, the mRNA levels of VPF/VEGF and two VPF/VEGF vascular endothelial cell receptors (Flt-1 and Flk-1) were all strikingly overexpressed in dermal microvascular cells [22]. Interestingly, tryptase, VEGF, and VEGF receptors all abundantly reside in the regions of dermal allergic and hypersensitive reactions. Based on the above reports, we hypothesized that tryptase may increase the dermal microvascular permeability as well as edema through regulating the expression of VEGF and VEGF receptors.

In the present study, we evaluated the effect of VEGF on hyperpermeability induced by purified human $\beta$-tryptase or human mast cell supernatant in cultured human dermal microvascular endothelial cells (HDMECs) and investigated the effect of tryptase and tryptase inhibitor (APC366) on VEGF and VEGF receptor (Flt-1, Flk-1) expression. The results provide the evidence that VEGF is involved in the increase of tryptase-induced microvascular permeability, which represents a novel pathway for controlling allergic reaction in skin.

\section{Materials and Methods}

Culture media, reagents, and SuperScript First-Strand Synthesis System for RT-PCR were purchased from Invitrogen (Carlsbad, CA, USA). SV Total RNA Isolation Kit was from Promega (Madison, WI, USA). SYBR Green real-time PCR Master Mix was from Toyobo Company (Osaka, JP). Primary antibody against von Willebrand factor (vWF), CD34, vascular endothelial growth factor (VEGF), fms-like tyrosine kinase (Flt-1), kinase insert domain containing receptor (Flk-1), and Glyceraldehydes-3-phosphate dehydrogenase (GAPDH) were purchased from SantaCruz Biotechnology, Inc. (Santa Cruz, CA). Antihuman VEGF Antibody for inhibiting VEGF was obtained from R\&D Systems (Minneapolis, MN, USA). SuperSignal West Pico Chemiluminescent Substrate was obtained from Pierce Biotechnology, Inc. (Rockford, IL, USA). $\beta$-trypatase was kindly provided by Dr. Shunlin Ren (Division of Gastroenterology, Virginia Commonwealth University, Richmond,VA, USA). All other reagents were from Sigma-Aldrich Chemical Co. (St. Louis, $\mathrm{MO})$ unless otherwise mentioned.

2.1. Isolation, Culture, and Identification of Human Dermal Microvascular Endothelial Cells (HDMECs). The method of HDMECs isolation and culture was set up based on literatures published previously [23-26]. Briefly, human neonatal foreskins were cut into small pieces and digested by $0.5 \mathrm{mg} / \mathrm{mL}$ Dispase dissolved in sodium acetate at $37^{\circ} \mathrm{C}$ for $1 \mathrm{~h}$. After removal of the epidermis, the dermal fragments were treated with $1 \%$ collagenase $\mathrm{I}$ at $37^{\circ} \mathrm{C}$ for $1 \mathrm{~h}$. The microvascular segments were passed through a 100$\mu \mathrm{m}$ nylon mesh cell strainer, collected, and purified by Percoll gradient centrifugation. The fraction with a density
$<1.048 \mathrm{~g} / \mathrm{mL}$, which was rich in microvascular fragments, was removed and applied to gelatin-precoated tissue-culture dishes and cultured in Dulbecco's modified Eagle's medium (DMEM; $1000 \mathrm{mg} / \mathrm{L}$ glucose) supplemented with $10 \mathrm{mM}$ HEPES, $10 \mathrm{mM}$ L-glutamine, $15 \mathrm{U} / \mathrm{mL}$ heparin, $1 \mu \mathrm{g} / \mathrm{mL}$ hydrocortisone acetate, $325 \mu \mathrm{g} / \mathrm{mL}$ glutathione, $0.05 \mathrm{mM}$ dibutyryl cyclic AMP, $5 \mu \mathrm{g} / \mathrm{mL}$ insulin, $5 \mu \mathrm{g} / \mathrm{mL}$ transferrin, $5 \mu \mathrm{M}$ 2-mercaptoethanol, $100 \mathrm{U} / \mathrm{mL}$ penicillin, $100 \mu \mathrm{g} / \mathrm{mL}$ streptomycin, and 20\% fatal bovine serum. The HDMECs were identified on the basis of morphological characteristics, immunofluorescent staining of von Willebrand factor (vWF) and CD34. All experiments used HDMECs at passages 2-4.

2.2. Culture of Human Mast Cell Line HMC-1. The human mast cell line HMC-1 was kindly obtained from Second Military Medical University, Shanghai, China. The cells were cultured in $75 \mathrm{~cm}^{2}$ flasks in Iscove's modified Dulbecco's medium (IMDM) supplemented with $10 \%$ fetal bovine serum (FBS), $100 \mathrm{IU} / \mathrm{mL}$ penicillin and $100 \mu \mathrm{g} / \mathrm{mL}$ streptomycin in humidified air with $5 \% \mathrm{CO}_{2}$ at $37^{\circ} \mathrm{C}$. Collected HMC-1 cells were activated and degranulated in the addition of prodegranulating agent a23187. The HMC-1 supernatant containing tryptase is collected, centrifuged, filtered, and then used as conditioned medium (henceforth referred as HMC-1 supernatant) in the following experiments. The activity of tryptase released from HMC-1 was quantified by monitoring hydrolysis of tosyl-L-Gly-ProLysp-nitroanilide (t6140) using a standard spectrophotometric assay at $405 \mathrm{~nm}$ wavelength. Tryptase was released from HMC-1 cells in a23187 (a prodegranulating agent) dose-dependent manner and HMC-1 cells density-dependent manner (Supplemental Figure 2 available online at doi:10.5402/2012/941465). The optimal stimulation and release were achieved by incubating HMC- 1 cells $\left(1 \times 10^{7} / \mathrm{mL}\right)$ for $2 \mathrm{~h}$ with a23187 $(1 \mu \mathrm{g} / \mathrm{mL})$ at $37^{\circ} \mathrm{C}$.

\subsection{Determination of Vascular Permeability in Cultured} HDMECs. As described in previous literature [27], HDMECs were grown to confluent monolayer on gelatin-coated membranes in double-chamber tissue culture plates (Transwell membrane, $0.4 \mu \mathrm{M}$ pore size, Corning Costar). After $48 \mathrm{~h}$, chambers were examined microscopically for integrity and uniformity of endothelial monolayers. The confluent monolayers were incubated with APC366 $(250 \mu \mathrm{g} / \mathrm{mL})$, antiVEGF antibody $(0.1 \mu \mathrm{g} / \mathrm{mL})$ or SU5614 $(5 \mu \mathrm{M})$ following its activation by either tryptase or HMC-1 supernatant for $18 \mathrm{~h}$ as described. At the end of the incubation period, FITCconjugated dextran ( $1 \mathrm{mg} / \mathrm{mL}, \mathrm{Mr}$ 42,000; Sigma-Aldrich) was added to the upper chambers, and fluorescence in the lower chamber was measured $1 \mathrm{~h}$ later with a fluorescence reader. Experiments were performed in triplicate and repeated 3 times.

2.4. Determination of Gene Expression of VEGF and Its Receptors. Total cell lysates of HDMECs were extracted on ice with 1\% NP40, 0.5\% sodium deoxycholate and $0.1 \%$ SDS in PBS with proteinase inhibitor cocktail (Sigma). Fifty $\mu \mathrm{g}$ total proteins were loaded on $7.5 \%$ SDS-PAGE for detection 
TABle 1: Primer pairs used to amplify PCR products.

\begin{tabular}{|c|c|c|c|c|}
\hline Gene & Sequence $\left(5^{\prime}-3^{\prime}\right)$ & Product size & Annealing $\mathrm{T}\left({ }^{\circ} \mathrm{C}\right)$ & GeneBank no. \\
\hline \multirow{2}{*}{ VEGF } & Forward: CAACATCACCATGCAGATTATGC & \multirow{2}{*}{$132 \mathrm{bp}$} & \multirow{2}{*}{$60^{\circ} \mathrm{C}$} & \multirow{2}{*}{ NM_001033756 } \\
\hline & Reverse: CCCACAGGGATTTTCTTGTCTT & & & \\
\hline \multirow{2}{*}{ Flt-1 } & Forward: TGGCTGCGACTCTCTTCTG & \multirow{2}{*}{$118 \mathrm{bp}$} & \multirow{2}{*}{$60^{\circ} \mathrm{C}$} & \multirow{2}{*}{ NM_002019 } \\
\hline & Reverse: CAAAGGAACTTCATCTGGGTCC & & & \\
\hline \multirow{2}{*}{ Flk-1 } & Forward: GGCCCAATAATCAGAGTGGCA & \multirow{2}{*}{$104 \mathrm{bp}$} & \multirow{2}{*}{$60^{\circ} \mathrm{C}$} & \multirow{2}{*}{ NM_002253 } \\
\hline & Reverse: TGTCATTTCCGATCACTTTTGGA & & & \\
\hline \multirow{2}{*}{ GAPDH } & Forward: CATGAGAAGTATGACAACAGCCT & \multirow{2}{*}{$113 \mathrm{bp}$} & \multirow{2}{*}{$60^{\circ} \mathrm{C}$} & \multirow{2}{*}{ NM_002046 } \\
\hline & Reverse: AGTCCTTCCACGATACCAAAGT & & & \\
\hline
\end{tabular}

of the specific proteins, including VEGF, and its receptors Flt-1 and Flk-1, using GAPDH as loading control. Western blot analysis was performed as previously described [28]. All Western blot experiments were repeated at least three times with separate cells preparation.

Total RNA was extracted using SV Total RNA Isolation Kit (Promega, Wisconsin, WI) according to the supplier's instructions. Two micrograms of total RNA were reversely transcribed and amplified. The relative mRNA levels were measured by real-time PCR as described previously [28]. Specific primer pairs for VEGF, Flt-1, Flk-1, and GAPDH were listed in Table 1.

2.5. Statistical Analysis. Data were presented as mean \pm SEM. Statistical significance was assessed by one-way ANOVA and discrepancies between groups were considered statistically significant at $P<0.05$.

\section{Results}

3.1. Culture and Identification of Human Dermal Microvascular Endothelial Cells (HDMECs). All HDMECs gave typical confluent cobblestone appearance (Supplemental Figure $1(\mathrm{a})$ ) and had positive reactions to the antibodies against vWF (Supplemental Figure 1(b)) and CD34 (Supplemental Figure 1(c)). Negative control without first antibody exhibited no staining (Supplemental Figure 1(d)). More than 90\% cells were positive for vWF and CD34, suggesting the purity of the primary cells exceeded $90 \%$.

3.2. Determination of the Tryptase Activity in HMC-1 Supernatant. To confirm the existence of tryptase in the conditioned medium, we incubated the HMC-1 supernatant with substrate (t6140, N-Tosylglycyl-L-prolyl-L-lysine 4nitroanilide acetate salt, $8 \mathrm{mmol} / \mathrm{L}$ ) in the presence and absence of prodegranulating agent a23187 $(1 \mu \mathrm{g} / \mathrm{mL})$ for 10 minutes in the reaction buffer $(40 \mathrm{mM}$ HEPES, $0.12 \mathrm{M}$ $\mathrm{NaCl}, \mathrm{pH}$ 7.4). OD value of the reaction was detected by spectrophotometer at $405 \mathrm{~nm}$ each 30 seconds. As shown in Supplemental Figure 2(a), the change of OD405 (formation of t6140-derived product digested by tryptase) was linear for at least 10 minutes, and 5 minutes was chosen as the reaction time. Tryptase was released in the HMC-1 supernatant, which is increased dramatically by prodegranulating agent a23187 (Supplemental Figure 2(b)). a23187 stimulated HMC-1 cells to release tryptase dose-dependently (Supplemental Figure 2(c)). On the other way, tryptase was released from HMC- 1 cells by $1 \mu \mathrm{g} / \mathrm{mL}$ a23187 in cell densitydependent manner (Supplemental Figure 2(d)). In the following experiments, HMC-1 supernatant was prepared by using $1 \times 10^{7} \mathrm{HMC}-1$ cells treated with $1 \mu \mathrm{g} / \mathrm{mL}$ a23187.

3.3. Effect of Tryptase/HMC-1 Supernatant on the Permeability of HDMECs. As described in the method, the amount of FITC-dextran in the lower chamber leaked from the HDMECs layer was detected to measure the permeability of HDMECs. The permeability of HDMECs with different treatments was quantified by the percentage of OD490 change. The confluent monolayers were treated with tryptase or HMC-1 supernatant for $18 \mathrm{~h}$ in the presence or absence of APC366 (a selective inhibitor of tryptase, $250 \mu \mathrm{g} / \mathrm{mL}$ ) pretreatment. As shown in Figure 1(a), tryptase significantly increased the permeability of HDMECs in a dose-dependent manner, which was resisted by APC366. Because $\beta$-tryptase was added into HDMECs accompanied by heparin as stabilizer, heparin control was also studied. It turns out that addition of heparin to HDMECs had no effect on the permeability. Figure 1(b) showed that HMC-1 supernatant enhanced the permeability of HDMECs dose-dependently, which was resisted by APC366. To investigate whether VEGF is involved in the hyperpermeability, anti-VEGF antibody $(0.1 \mu \mathrm{g} / \mathrm{mL})$ was preincubated on HDMECs to block VEGF. The data was normalized to groups treated with normal goat IgG. As a result, inhibition of VEGF significantly attenuated tryptase-induced permeability (Figure 1(c)), but only modestly attenuated HMC-1 supernatant-induced permeability (Figure 1(d)). SU5614, 3-[(2,4-demethylpyrrol-5yl)methylidene]-indolin-2-one, is a small synthetic inhibitor of the catalytic function of the VEGF receptor (VEGFR-2; Flk-1/KDR) tyrosine kinase. It was used to strengthen the evidence that VEGF is involved in the hypermeability caused by tryptase. As shown in Figure 1(c), pretreatment of $5 \mu \mathrm{M}$ SU5416 with HDMECs dramatically attenuated tryptaseinduced hypermeability.

3.4. Effect of Tryptase on the VEGF, Flt-1, and Flk-1 Protein Levels in HDMECs. To study the mechanism of resistance of tryptase-induced hyperpermeability by antiVEGF antibody, the protein levels of VEGF, Flt-1, and Flk-1 in HDMECs of indicated treatments were analyzed 


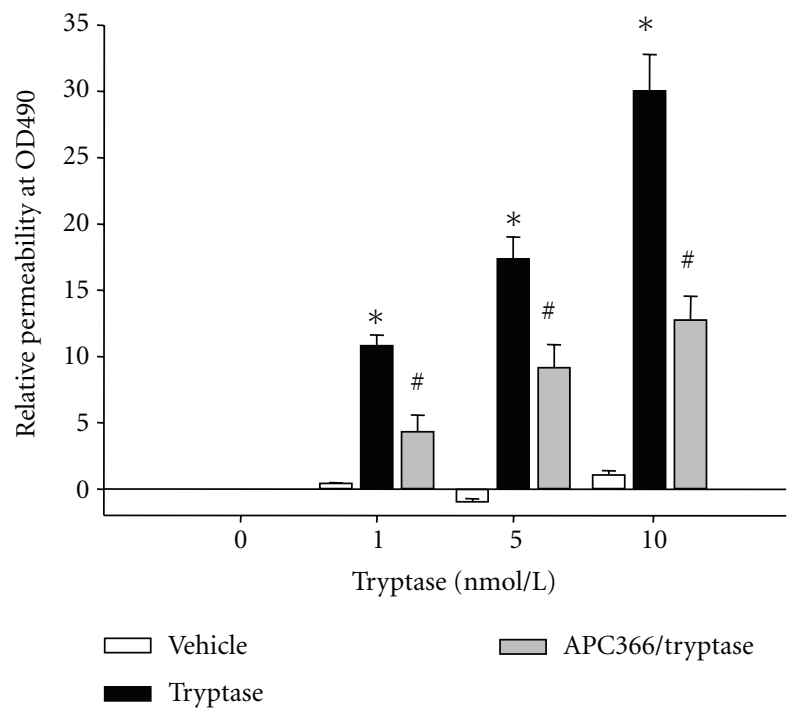

(a)

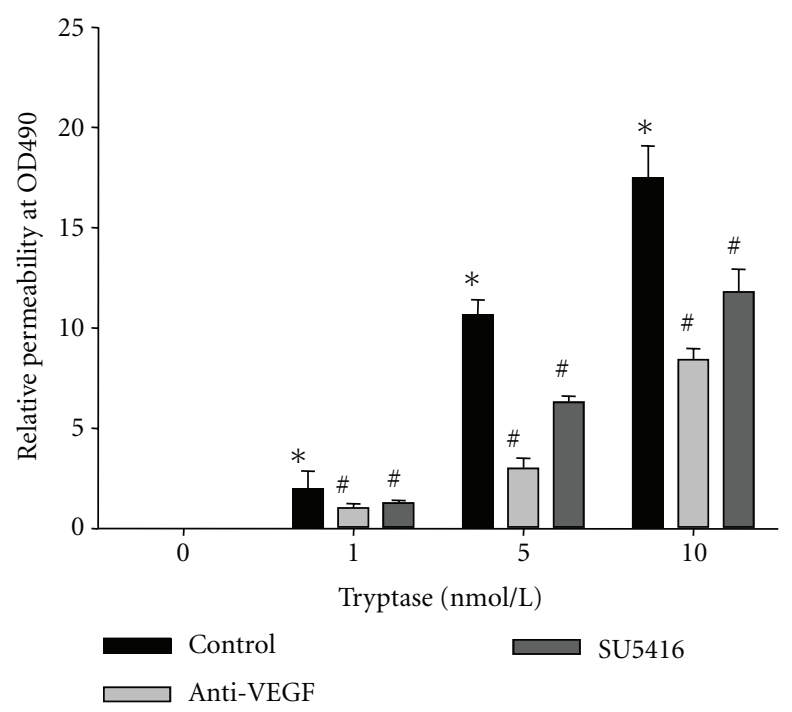

(c)

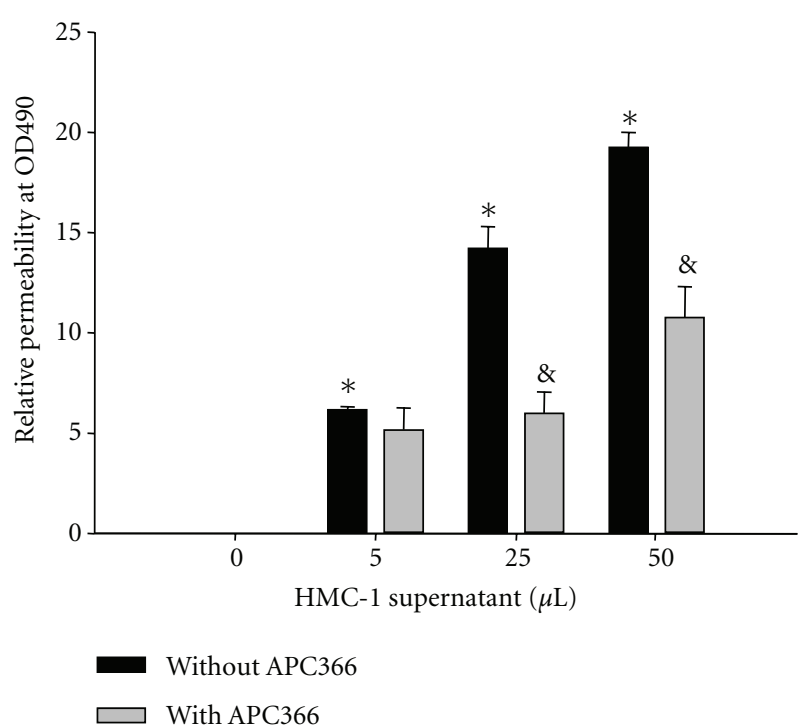

(b)

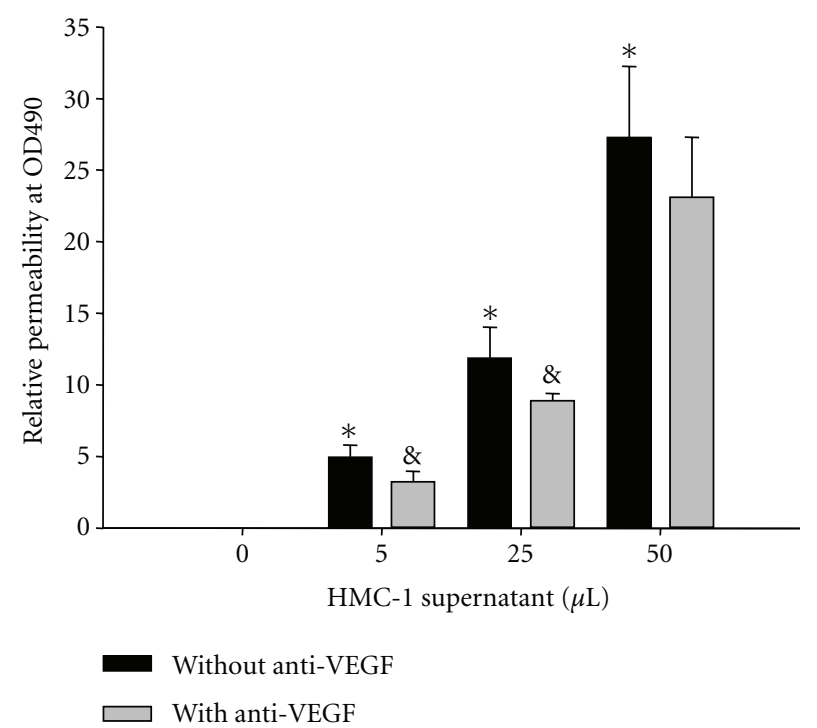

(d)

FIGURE 1: Effect of tryptase and HMC-1 supernatant on the permeability of HDMECs. As described in Methods, the permeability of HDMECs after indicated treatment was detected by measuring fluorescence in the lower chamber at $490 \mathrm{~nm}$ after incubation with FITCdextran for $1 \mathrm{~h}$ in the upper chamber. The changes of OD490 in the lower chamber after $1 \mathrm{~h}$ of incubation were calculated for the permeability of HDMECs. (a) Effect of tryptase at different concentrations on the permeability of HDMECs in the presence or absence of APC366. The heparin was used as Vehicle control. (b) Effect of HMC-1 supernatant at different concentrations on the permeability of HDMECs with or without APC366. (c) Effect of anti-VEGF antibody and SU5416 on the increase of permeability stimulated by tryptase. (d) Effect of anti-VEGF antibody on the increase of permeability stimulated by HMC-1 supernatant. ${ }^{*} P<0.05$ compared to the group of nonaddition. ${ }^{\#} P<0.05$ compared to the group only treated with tryptase. ${ }^{\circledR} P<0.05$ compared to the group only treated with HMC-1 supernatant.

by Western blot. Different concentrations of tryptase were added into HDMECs for $18 \mathrm{~h}$ in the absence or presence of APC366. The heparin control was also analyzed. As a result, addition of different concentration of tryptase to HDMECs in culture significantly increased the protein levels of VEGF (Figure 2(a)), Flt-1 (Figure 2(b)), and Flk-1 (Figure 2(c)), which was resisted by APC 366, a synthetic tryptase inhibitor. However, there was no effect on these protein expressions following the treatment of heparin control.
3.5. Effect of Tryptase on the VEGF, Flt-1, and Flk-1 mRNA Levels in HDMECs. To further study the mechanism of resistance of tryptase-induced hyperpermeability by antiVEGF antibody, the effect of tryptase on VEGF, Flt-1, and Flk-1 expressions in HDMECs at mRNA level was analyzed by Real-time RT-PCR. GAPDH was determined in parallel and used as an internal standard. Different concentrations of tryptase were added into HDMECs for $6 \mathrm{~h}$. The expression levels were normalized to heparin control. As shown in 


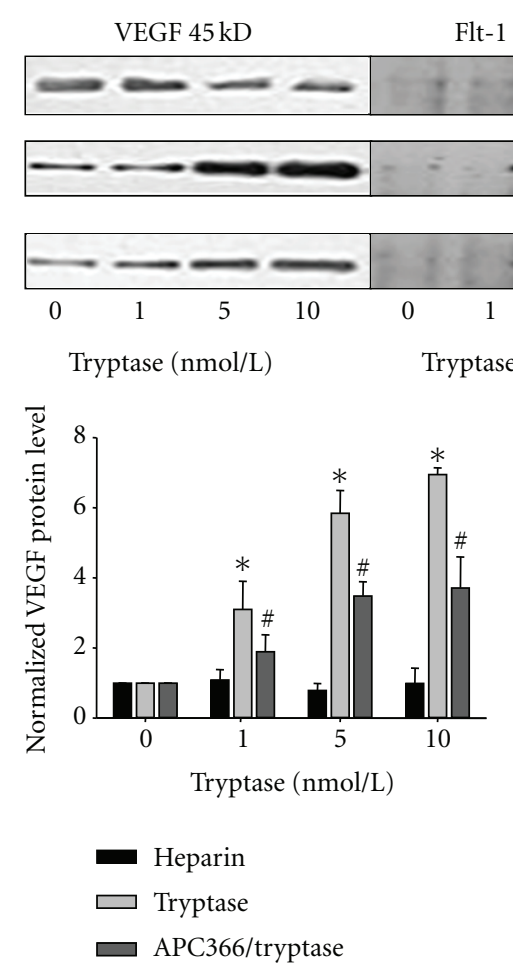

(a) $180 \mathrm{kD}$
Flk-1 $220 \mathrm{kD}$
GAPDH $34 \mathrm{kD}$
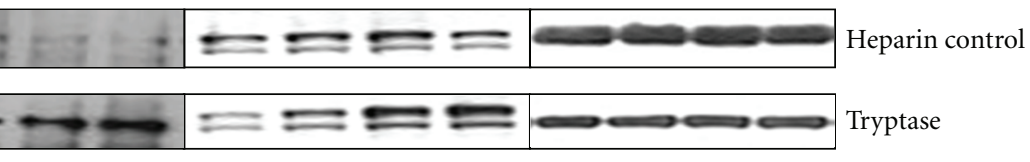

$\simeq=$ $=2$
Tryptase

Tryptase + APC366

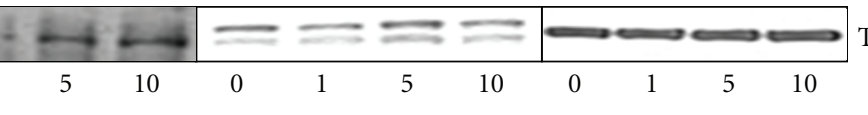

Tryptase (nmol/L)

Tryptase (nmol/L)

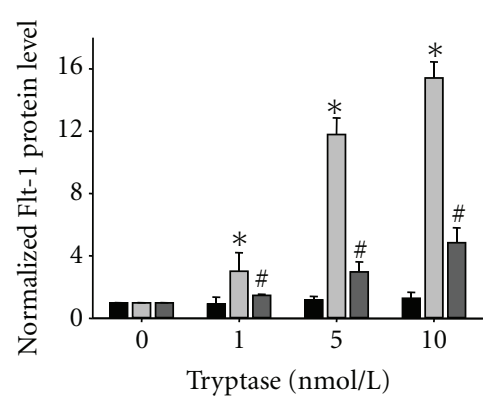

$\square$ Heparin
$\square$ Tryptase
$\square$ APC366/tryptase

(b)

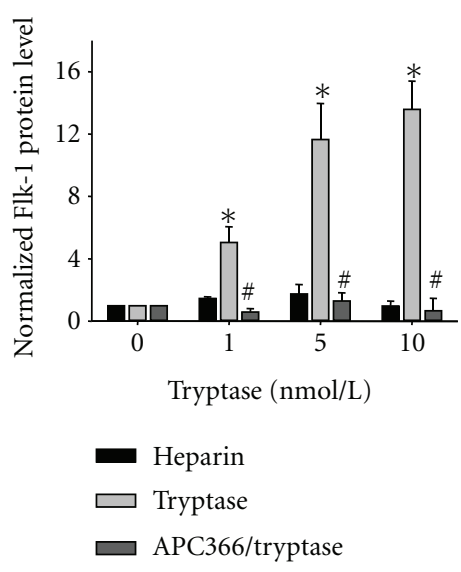

(c)

FIGURE 2: Effect of tryptase on the VEGF, Flt-1, and Flk-1 protein levels in HDMECs with or without APC366. HDMECs were treated with different concentrations of tryptase for $18 \mathrm{~h}$ in the absence or presence of APC366 $(250 \mu \mathrm{g} / \mathrm{mL})$. The protein levels of VEGF (a), Flt-1 (b), and Flk-1 (c) were determined by Western blot and normalized to GAPDH. The heparin control was also analyzed. ${ }^{*} P<0.05$ compared to the group of nonaddition. ${ }^{\#} P<0.05$ compared to the group only treated with tryptase at the same concentration.

Figure 3, tryptase upregulated VEGF, Flt-1, and Flk-1 mRNA levels significantly.

\section{Discussion}

In the present study, we demonstrated that both mast cell tryptase and HMC-1 supernatant promote vascular hyperpermeability in cultured human dermal microvascular endothelial cells (HDMECs), which can be significantly blocked by anti-VEGF and SU5416 (inhibitor of VEGF receptor, VEGFR-2/Flk-1). Furthermore, tryptase increases the expression of VEGF and its receptors (Flt-1 and Flk-1), which can be inhibited by synthetic tryptase inhibitor (APC366). These results provide the evidence that VEGF is involved in the increase of tryptase-induced microvascular permeability, which represents a novel pathway for controlling allergic reaction in skin.

Tryptases are predominantly mast cell-specific serine proteases with pleiotropic biological activities $[8,29]$. Under physiological conditions, tryptases are primarily detectable in mast cells and basophils and at least consist of $\alpha$-tryptase and $\beta$-tryptase. $\beta$-tryptase appears to be the main isoenzyme that is expressed in human lung and skin mast cells, whereas in basophils $\alpha$-tryptase predominates [30]. $\beta$-tryptase with physiological activities exists as tetrameric conformation, which is ionically bound to heparin proteoglycan [31].
Heparin stabilizes tryptase in its enzymatically active form $[32,33]$. Therefore, heparin proteoglycan with identical concentrations was used as Vehicle control in our experiments.

Increasing evidences indicate that mast cell tryptase plays an important role in enhancement of vascular permeability [14-17]. Mast cell tryptase increases intracellular $\mathrm{Ca}^{2+}$, leading to elevation of paracellular permeability of colonocytes [15]. Mast cells control permeability of the intestinal epithelium by cleaving protease-activated receptor $2\left(\mathrm{PAR}_{2}\right)$ on the basolateral membrane of colonocytes and activating extracellular signal-regulated kinases 1/2 (ERK1/2) [15, 17]. Our data also demonstrated that either purified tryptase or HMC-1-released tryptase stimulated vascular permeability in primary human dermal microvascular endothelial cells (HDMECs), which can be partly inhibited by synthetic tryptase inhibitor (APC366) (Figure 1). Tryptase inhibitors reduced but did not abolish the effects of HMC-1 mast cell supernatant on permeability of HDMECs, suggesting that mast cell mediators other than tryptase may also regulate vascular permeability.

In addition to tryptase, mast cells release a number of mediators that act directly on the vasculature to produce vasodilatation and increase permeability, including vascular endothelial growth factor (VEGF) [34]. VEGF is an endothelial cell-specific mitogenic peptide and plays a key role in 


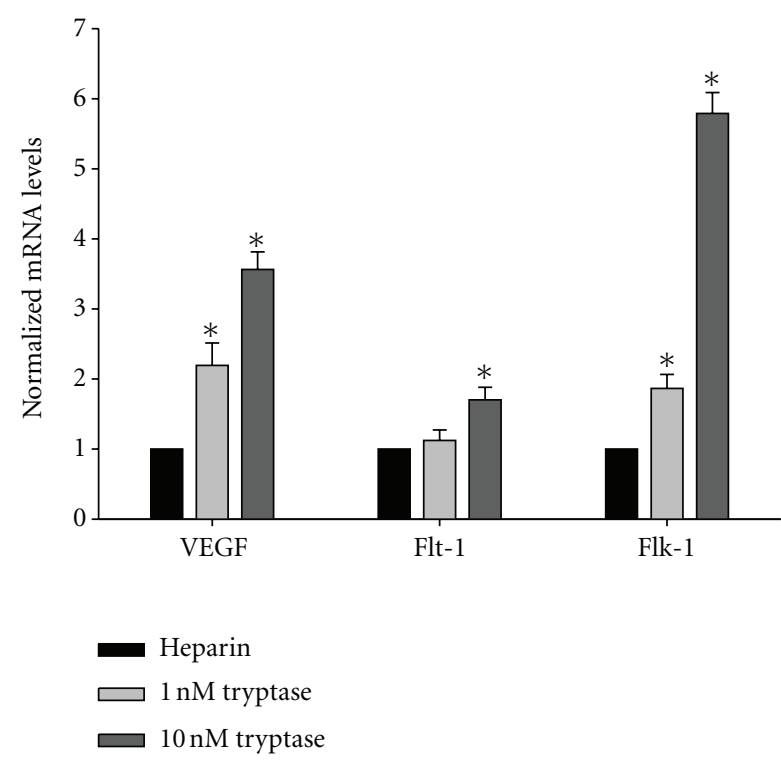

FIGURE 3: Effect of tryptase on the VEGF, Flt-1, and Flk-1 mRNA levels in HDMECs. Different concentrations of tryptase (0, 1, and $10 \mathrm{nmol} / \mathrm{L}$ ) were added into HDMECs for $6 \mathrm{~h}$. The mRNA levels of VEGF (a), Flt-1 (b), and Flk-1 (c) were determined by Real-time RT-PCR and normalized to GAPDH. The heparin control was also analyzed. ${ }^{*} P<0.05$ compared to the group of heparin control.

vasculogenesis, angiogenesis, and stimulation of vascular permeability [35-38]. The VEGF family includes VEGFA, placenta growth factor (PlGF), VEGF-B, VEGF-C, and VEGF-D. The original member of the VEGF family, VEGF-A, also known as vascular permeability factor, was characterized as a potent inducer of vascular permeability $[19,35,39$, 40]. In the present work, VEGF-A is represented as VEGF. VEGF binding to the 2 types III receptor tyrosine kinases VEGF receptor-1 (VEGFR-1/Flt-1) and VEGFR-2 (Flk-1) are primarily expressed in vascular endothelial cells. Previous studies have revealed that VEGF expressions by epidermal keratinocytes and endothelial expression of VEGF receptors are upregulated in cutaneous inflammation [21]. However, whether VEGF and its receptors are involved in the tryptaseinduced hyperpermeability is unknown. Therefore, in the present study, we investigated the effect of tryptase on the expressions of VEGF and its receptors (Flt-1 and Flk-1). The results showed that tryptase significantly increased the mRNA and protein levels of VEGF and its receptors in HDMECs, which can be inhibited by APC366 (Figures 2 and 3). Furthermore, SU5614, a potent inhibitor of VEGF, and anti-VEGF effectively resisted the tryptase-induced hyperpermeability (Figure 1). Hereby, VEGF is at least partially responsible to the enhancement of permeability induced by tryptase. However, the specific mechanism of how tryptase stimulates expression of VEGF and its receptors should be elucidated in the further study.

In conclusion, mast cells tryptase significantly increased the expressions of VEGF and its receptors (Flt-1 and Flk1) and promoted microvascular permeability in HDMECs, which can be reversed by VEGF inhibitor. The results indicated that VEGF is involved in the increase of dermal microvascular hyperpermeability by tryptase. These findings may lead to novel means of controlling allergic reaction in skin.

\section{Acknowledgments}

This work was supported by CMA-L'OREAL China Skin/ Hair Grant funds and National Natural Science Foundation of China (NSFC 30871021 and NSFC 30800547).

\section{References}

[1] S. J. Galli and M. Tsai, "Mast cells in allergy and infection: versatile effector and regulatory cells in innate and adaptive immunity," European Journal of Immunology, vol. 40, no. 7, pp. 1843-1851, 2010.

[2] E. Garbuzenko, A. Nagler, D. Pickholtz et al., "Human mast cells stimulate fibroblast proliferation, collagen synthesis and lattice contraction: a direct role for mast cells in skin fibrosis," Clinical and Experimental Allergy, vol. 32, no. 2, pp. 237-246, 2002.

[3] D. A. Groneberg, F. Serowka, N. Peckenschneider et al., "Gene expression and regulation of nerve growth factor in atopic dermatitis mast cells and the human mast cell line-1," Journal of Neuroimmunology, vol. 161, no. 1-2, pp. 87-92, 2005.

[4] T. C. Theoharides and D. E. Cochrane, "Critical role of mast cells in inflammatory diseases and the effect of acute stress," Journal of Neuroimmunology, vol. 146, no. 1-2, pp. 1-12, 2004.

[5] J. Kalesnikoff and S. J. Galli, "New developments in mast cell biology," Nature Immunology, vol. 9, no. 11, pp. 1215-1223, 2008.

[6] M. Metz, M. A. Grimbaldeston, S. Nakae, A. M. Piliponsky, M. Tsai, and S. J. Galli, "Mast cells in the promotion and limitation of chronic inflammation," Immunological Reviews, vol. 217, no. 1, pp. 304-328, 2007.

[7] K. Norrby, "Mast cells and angiogenesis: review article," APMIS, vol. 110, no. 5, pp. 355-371, 2002.

[8] L. B. Schwartz, K. Sakai, T. R. Bradford et al., "The $\alpha$ form of human tryptase is the predominant type present in blood at baseline in normal subjects and is elevated in those with 
systemic mastocytosis," Journal of Clinical Investigation, vol. 96, no. 6, pp. 2702-2710, 1995.

[9] S. Jogie-Brahim, H. K. Min, Y. Fukuoka, H. Z. Xia, and L. B. Schwartz, "Expression of alpha-tryptase and beta-tryptase by human basophils," Journal of Allergy and Clinical Immunology, vol. 113, no. 6, pp. 1086-1092, 2004.

[10] Y. Fukuoka and L. B. Schwartz, "Human $\beta$-tryptase: detection and characterization of the active monomer and prevention of tetramer reconstitution by protease inhibitors," Biochemistry, vol. 43, no. 33, pp. 10757-10764, 2004.

[11] Y. Fukuoka and L. B. Schwartz, "The B12 anti-tryptase monoclonal antibody disrupts the tetrameric structure of heparinstabilized $\beta$-tryptase to form monomers that are inactive at neutral $\mathrm{pH}$ and active at acidic $\mathrm{pH}$," Journal of Immunology, vol. 176, no. 5, pp. 3165-3172, 2006.

[12] G. Bazzoni and E. Dejana, "Endothelial cell-to-cell junctions: molecular organization and role in vascular homeostasis," Physiological Reviews, vol. 84, no. 3, pp. 869-901, 2004.

[13] O. E. Kolokitha and E. Chatzistavrou, "Allergic reactions to nickel-containing orthodontic appliances: clinical signs and treatment alternatives," World Journal of Orthodontics, vol. 9, no. 4, pp. 399-406, 2008.

[14] T. Imamura, A. Dubin, W. Moore, R. Tanaka, and J. Travis, "Induction of vascular permeability enhancement by human tryptase: dependence on activation of prekallikrein and direct release of bradykinin from kininogens," Laboratory Investigation, vol. 74, no. 5, pp. 861-870, 1996.

[15] C. Jacob, P. C. Yang, D. Darmoul et al., "Mast cell tryptase controls paracellular permeability of the intestine: role of protease-activated receptor 2 and $\beta$-arrestins," Journal of Biological Chemistry, vol. 280, no. 36, pp. 31936-31948, 2005.

[16] M. Lytinas, D. Kempuraj, M. Huang et al., "Azelastine's inhibition of histamine and tryptase release from human umbilical cord blood-derived cultured mast cells as well as rat skin mast cell-induced vascular permeability: comparison with olopatadine," Allergy and Asthma Proceedings, vol. 23, no. 1, pp. 45-51, 2002.

[17] Y. Itoh, T. Sendo, and R. Oishi, "Physiology and pathophysiology of proteinase-activated receptors (PARs): role of tryptase/PAR-2 in vascular endothelial barrier function," Journal of Pharmacological Sciences, vol. 97, no. 1, pp. 14-19, 2005.

[18] T. Murohara, J. R. Horowitz, M. Silver et al., "Vascular endothelial growth factor/vascular permeability factor enhances vascular permeability via nitric oxide and prostacyclin," Circulation, vol. 97, no. 1, pp. 99-107, 1998.

[19] D. O. Bates and S. J. Harper, "Regulation of vascular permeability by vascular endothelial growth factors," Vascular Pharmacology, vol. 39, no. 4-5, pp. 225-237, 2002.

[20] D. Feng, J. A. Nagy, R. A. Brekken et al., "Ultrastructural localization of the vascular permeability factor/vascular endothelial growth factor (VPF/VEGF) receptor-2 (FLK-1, KDR) in normal mouse kidney and in the hyperpermeable vessels induced by VPF/VEGF- expressing tumors and adenoviral vectors," Journal of Histochemistry and Cytochemistry, vol. 48, no. 4, pp. 545-556, 2000.

[21] L. F. Brown, S. M. Olbricht, B. Berse et al., "Overexpression of vascular permeability factor (VPF/VEGF) and its endothelial cell receptors in delayed hypersensitivity skin reactions," Journal of Immunology, vol. 154, no. 6, pp. 2801-2807, 1995.

[22] Y. Zhang, H. Matsuo, and E. Morita, "Increased production of vascular endothelial growth factor in the lesions of atopic dermatitis," Archives of Dermatological Research, vol. 297, no. 9, pp. 425-429, 2006.
[23] P. M. Davison, K. Bensch, and M. A. Karasek, "Isolation and growth of endothelial cells from the microvessels of the newborn human foreskin in cell culture," Journal of Investigative Dermatology, vol. 75, no. 4, pp. 316-321, 1980.

[24] P. M. Davison and M. A. Karasek, "Human dermal microvascular endothelial cells in vitro: effect of cyclic AMP on cellular morphology and proliferation rate," Journal of Cellular Physiology, vol. 106, no. 2, pp. 253-258, 1981.

[25] R. M. Marks, M. Czerniecki, and R. Penny, "Human dermal microvascular endothelial cells: an improved method for tissue culture and a description of some singular properties in culture," In Vitro Cellular \& Developmental Biology, vol. 21, no. 11, pp. 627-635, 1985.

[26] K. Gupta, S. Ramakrishnan, P. V. Browne, A. Solovey, and R. P. Hebbel, "A novel technique for culture of human dermal microvascular endothelial cells under either serumfree or serum-supplemented conditions: isolation by panning and stimulation with vascular endothelial growth factor," Experimental Cell Research, vol. 230, no. 2, pp. 244-251, 1997.

[27] V. V. Orlova, M. Economopoulou, F. Lupu, S. Santoso, and T. Chavakis, "Junctional adhesion molecule-C regulates vascular endothelial permeability by modulating VE-cadherinmediated cell-cell contacts," Journal of Experimental Medicine, vol. 203, no. 12, pp. 2703-2714, 2006.

[28] Q. Bai, L. Xu, G. Kakiyama et al., "Sulfation of 25-hydroxycholesterol by SULT2B1b decreases cellular lipids via the LXR/SREBP-1c signaling pathway in human aortic endothelial cells," Atherosclerosis, vol. 214, no. 2, pp. 350-356, 2011.

[29] X. P. Yang, Y. Li, Y. Wang, Y. Wang, and P. Wang, “ $\beta$-Tryptase up-regulates vascular endothelial growth factor expression via proteinase-activated receptor-2 and mitogen-activated protein kinase pathways in bone marrow stromal cells in acute myeloid leukemia," Leukemia \& Lymphoma, vol. 51, no. 8, pp. 1550$1558,2010$.

[30] C. P. Sommerhoff, W. Bode, G. Matschiner, A. Bergner, and H. Fritz, "The human mast cell tryptase tetramer: a fascinating riddle solved by structure," Biochimica et Biophysica Acta, vol. 1477, no. 1-2, pp. 75-89, 2000.

[31] S. Ren, A. E. Lawson, M. Carr, C. M. Baumgarten, and L. B. Schwartz, "Human tryptase fibrinogenolysis is optimal at acidic $\mathrm{pH}$ and generates anticoagulant fragments in the presence of the anti-tryptase monoclonal antibody B12," Journal of Immunology, vol. 159, no. 7, pp. 3540-3548, 1997.

[32] L. B. Schwartz, "Tryptase: a mast cell serine protease," Methods in Enzymology, vol. 244, pp. 88-100, 1994.

[33] R. J. Blair, H. Meng, M. J. Marchese et al., "Human mast cells stimulate vascular tube formation. tryptase is a novel, potent angiogenic factor," Journal of Clinical Investigation, vol. 99, no. 11, pp. 2691-2700, 1997.

[34] D. D. Metcalfe, D. Baram, and Y. A. Mekori, "Mast cells," Physiological Reviews, vol. 77, no. 4, pp. 1033-1079, 1997.

[35] H. F. Dvorak, L. F. Brown, M. Detmar, and A. M. Dvorak, "Vascular permeability factor/vascular endothelial growth factor, microvascular hyperpermeability, and angiogenesis," The American Journal of Pathology, vol. 146, no. 5, pp. 10291039, 1995.

[36] Y. C. Lee, Y. G. Kwak, and C. H. Song, "Contribution of vascular endothelial growth factor to airway hyperresponsiveness and inflammation in a murine model of toluene diisocyanateinduced asthma," Journal of Immunology, vol. 168, no. 7, pp. 3595-3600, 2002.

[37] C. G. Lee, H. Link, P. Baluk et al., "Vascular endothelial growth factor (VEGF) induces remodeling and enhances 
TH2-mediated sensitization and inflammation in the lung," Nature Medicine, vol. 10, no. 10, pp. 1095-1103, 2004.

[38] K. S. Lee, S. R. Kim, H. S. Park, G. Y. Jin, and Y. C. Lee, "Cysteinyl leukotriene receptor antagonist regulates vascular permeability by reducing vascular endothelial growth factor expression," Journal of Allergy and Clinical Immunology, vol. 114, no. 5, pp. 1093-1099, 2004.

[39] H. F. Dvorak, "Discovery of vascular permeability factor (VPF)," Experimental Cell Research, vol. 312, no. 5, pp. 522526, 2006.

[40] D. Ribatti, "The crucial role of vascular permeability factor/vascular endothelial growth factor in angiogenesis: a historical review," British Journal of Haematology, vol. 128, no. 3, pp. 303-309, 2005. 


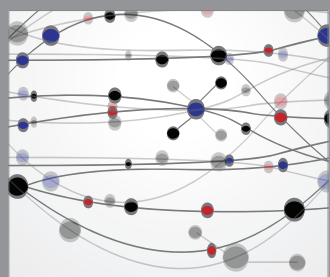

The Scientific World Journal
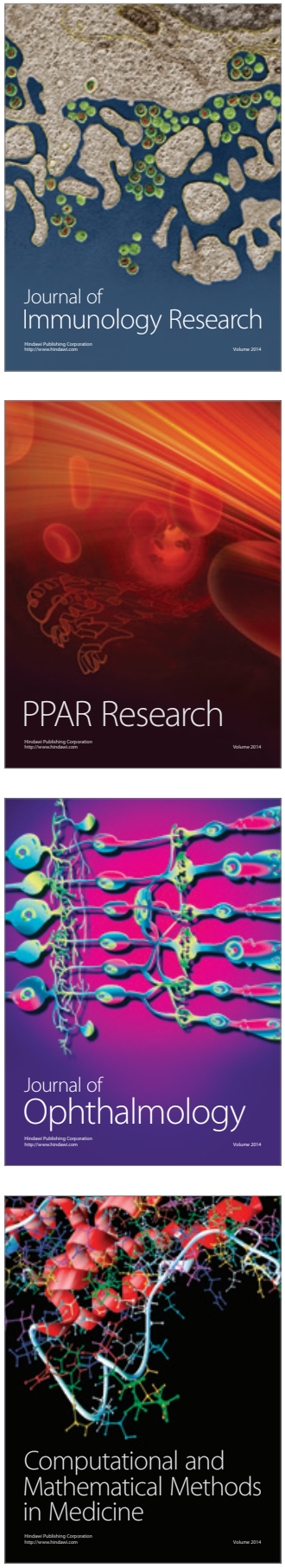

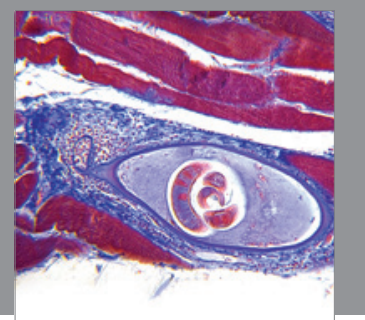

Gastroenterology

Research and Practice
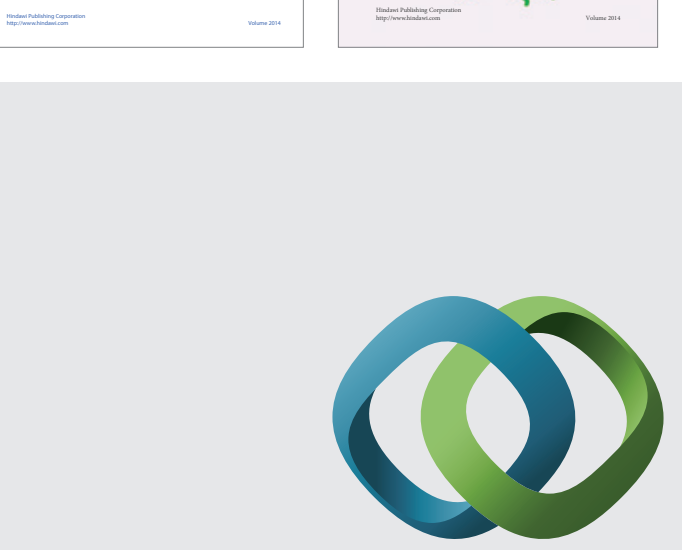

\section{Hindawi}

Submit your manuscripts at

http://www.hindawi.com
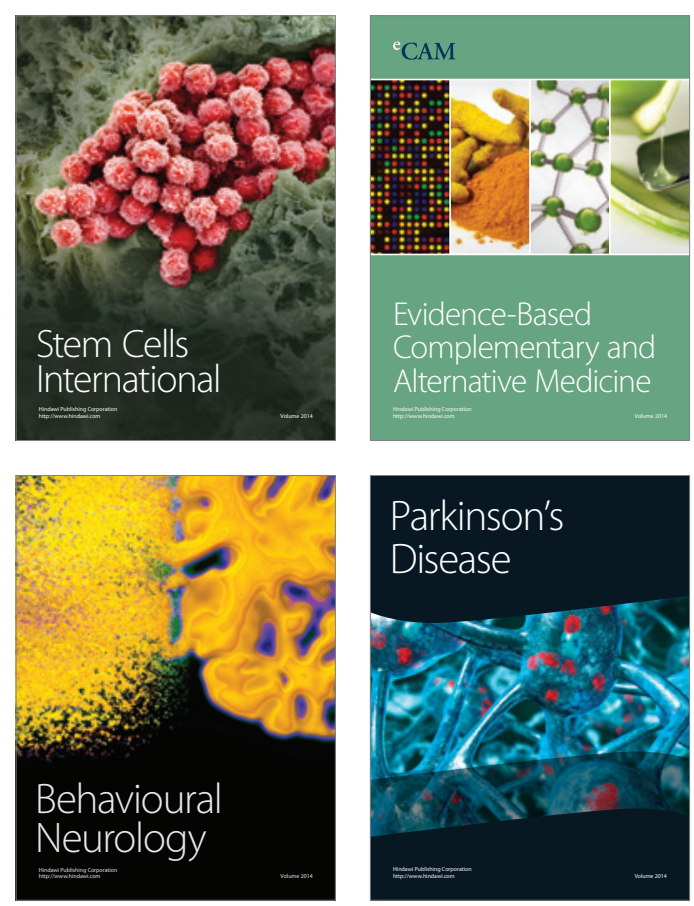

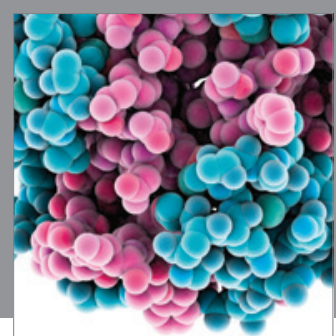

Journal of
Diabetes Research

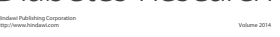

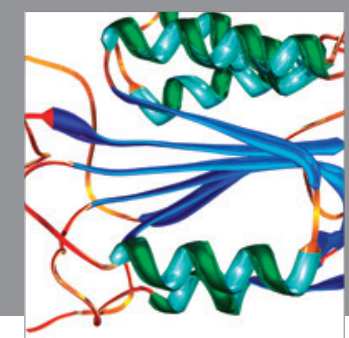

Disease Markers
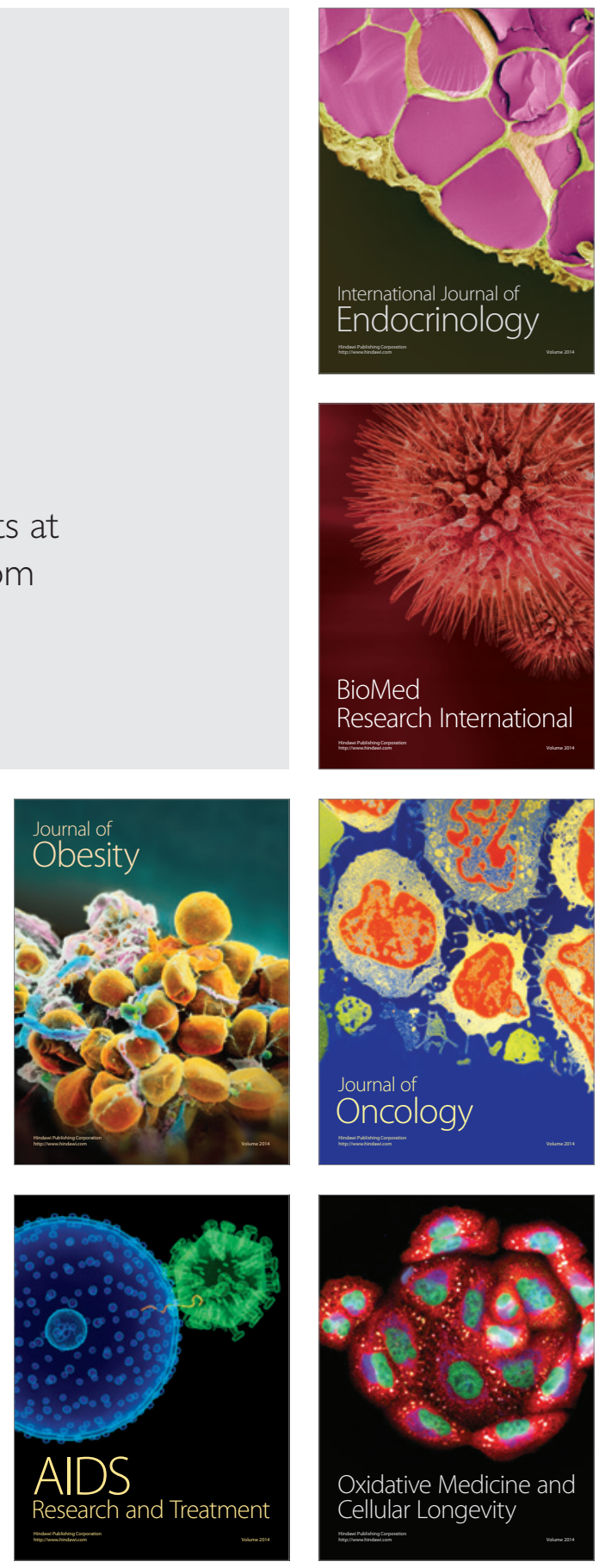